\title{
Metformin use and early lactate levels in critically ill patients according to chronic and acute renal impairment
}

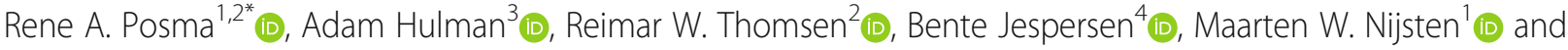 \\ Christian F. Christiansen ${ }^{2}$ (I)
}

Keywords: Metformin, Lactate, Acute kidney injury, Chronic kidney disease, Metformin-associated lactic acidosis, Critical care

\section{Main text}

Metformin is the most widely used oral antihyperglycemic agent. Because it is eliminated unmodified in urine, patients with renal insufficiency can accumulate metformin and may develop lactic acidosis [1]. Recent guidelines only restrict the use of metformin in patients with severe chronic kidney disease (CKD) because the benefit is considered larger than the risk for lactic acidosis [2]. Lactate measurement has a central role in identifying and monitoring critical illness [3]. A better understanding of the impact of metformin on lactate levels could improve clinical assessment of the critically ill.

Data were collected by combining data from Danish nationwide medical databases with laboratory data [4]. This multicenter cohort included all adults ( $\geq 18$ years) hospitalized and surviving $24 \mathrm{~h}$ of intensive care unit (ICU) treatment in northern Denmark between January 2010 and August 2017. We required $\geq 3$ lactate measurements between $6 \mathrm{~h}$ before until $24 \mathrm{~h}$ after ICU admission, with $\geq 12 \mathrm{~h}$ between first and last measurement. Patients receiving dialysis before ICU admission were excluded.

Metformin use was defined as a filled prescription for metformin within 90 days before ICU admission [4]. CKD

\footnotetext{
* Correspondence: r.a.posma@umcg.nl

'Department of Critical Care, University of Groningen, University Medical Center Groningen, Groningen, The Netherlands

${ }^{2}$ Department of Clinical Epidemiology, Aarhus University Hospital, Aarhus, Denmark

Full list of author information is available at the end of the article
}

stage was assessed by the mean estimated glomerular filtration rate (eGFR) 365 days until 7 days before ICU admission [5]. Acute kidney injury (AKI) within $24 \mathrm{~h}$ after ICU admission was defined and staged according to the KDIGO creatinine criteria. Lactate trajectories over time for metformin users and nonusers were fitted by a mixed-effects model assuming unstructured covariance and including individuallevel random intercept and slope. Time was modeled as a natural cubic spline with knot locations at $-1 \mathrm{~h},+4 \mathrm{~h}$, and $+12 \mathrm{~h}$ relative to ICU admission. Time-by-group interaction was entered as a covariate, and analyses were subsequently stratified by eGFR level or AKI stage. Differences in maximum lactate level with $95 \%$ confidence intervals between metformin users and nonusers were model-based.

We studied 20,741 patients with a total of 209,394 lactate measurements, of whom 1905 (9\%) patients used metformin (Table 1). Compared with nonusers, metformin users had a similar preadmission eGFR but had more often AKI stage 2 or 3. Metformin users had $0.61(0.45-0.77) \mathrm{mmol} /$ $\mathrm{L}$ higher maximum lactate levels than nonusers (Fig. 1a). This difference was highest for patients with eGFR $\leq 45$ $\mathrm{ml} / \mathrm{min} / 1.73 \mathrm{~m}^{2}$ (1.06 [0.72-1.39] mmol/L; Fig. 1b). Differences in maximum lactate levels between metformin users and nonusers were more pronounced in patients with AKI stage 2 or 3 (Fig. 1c), with a difference of $0.30(0.15-0.45)$ $\mathrm{mmol} / \mathrm{L}$ for patients without AKI, and $0.12(-0.24$ to 0.48$)$, 1.00 (0.35-1.65), and $1.75(1.03-2.47) \mathrm{mmol} / \mathrm{L}$ among patients with AKI stage 1, 2, or 3, respectively. The difference between metformin users and nonusers disappeared within 
Table 1 Characteristics of metformin users and nonusers

\begin{tabular}{|c|c|c|c|c|}
\hline Characteristic & $\begin{array}{l}\text { Total }(N=20, \\
741)\end{array}$ & $\begin{array}{l}\text { Metformin users }(N= \\
1905)\end{array}$ & $\begin{array}{l}\text { Metformin nonusers }(N=18 \text {, } \\
836)\end{array}$ & SMD* $^{*}$ \\
\hline Age, median [IQR], years & $69[58-77]$ & $70[63-76]$ & $69[58-77]$ & 0.24 \\
\hline Male sex & $11,697(56)$ & $1193(63)$ & $10,504(56)$ & 0.14 \\
\hline Charlson Comorbidity Index & & & & 0.52 \\
\hline 0 & $6894(33)$ & $305(16)$ & $6589(35)$ & \\
\hline 1 or 2 & 8147 (39) & 737 (39) & 7410 (39) & \\
\hline 3 or higher & $5700(27)$ & $863(45)$ & $4837(26)$ & \\
\hline Diabetes mellitus & $4594(22)$ & $1903(100)$ & $2691(14)$ & 3.45 \\
\hline Sulfonylureas & $476(2)$ & $250(13)$ & $226(1)$ & 0.48 \\
\hline Insulin & $1473(7)$ & $443(23)$ & $1030(5)$ & 0.52 \\
\hline Other antihyperglycemic agents & $445(2)$ & $259(14)$ & $186(1)$ & 0.50 \\
\hline Preadmission eGFR, median [IQR], $\mathrm{ml} / \mathrm{min} / 1.73 \mathrm{~m}^{2}$ & 80 [58-95] & $77[58-92]$ & $80[58-95]$ & 0.07 \\
\hline$\geq 60 \mathrm{ml} / \mathrm{min} / 1.73 \mathrm{~m}^{2}$ & $12,892(62)$ & $1345(71)$ & $11,547(61)$ & 0.48 \\
\hline $45-60 \mathrm{ml} / \mathrm{min} / 1.73 \mathrm{~m}^{2}$ & $2189(11)$ & $278(15)$ & $1911(10)$ & \\
\hline$\leq 45 \mathrm{ml} / \mathrm{min} / 1.73 \mathrm{~m}^{2}$ & $2442(12)$ & $221(12)$ & $2221(12)$ & \\
\hline Missing & $3218(16)$ & $61(3)$ & $3157(17)$ & \\
\hline ICU admission type & & & & 0.20 \\
\hline Medical & $9942(48)$ & $1019(53)$ & $8923(47)$ & \\
\hline Emergency surgical & $6344(31)$ & $456(24)$ & $5888(31)$ & \\
\hline Elective surgical & $3149(15)$ & $345(18)$ & $2804(15)$ & \\
\hline Missing & $1306(6)$ & $85(4)$ & $1221(6)$ & \\
\hline $\begin{array}{l}\text { Time from hospital admission to ICU admission, median } \\
\text { [IQR], } \mathrm{h}^{\dagger}\end{array}$ & $5.1[0.0-30.5]$ & $5.3[0.0-29.4]$ & $5.1[0.0-30.7]$ & 0.06 \\
\hline SAPS-II score, median [IQR] & $40[30-52]$ & $42[31-53]$ & $40[30-52]$ & 0.09 \\
\hline Missing & $11,456(55)$ & $1024(54)$ & $10,432(55)$ & \\
\hline Mechanical ventilation & $9305(45)$ & $815(43)$ & $8490(45)$ & 0.05 \\
\hline Inotropes or vasopressors & $8943(43)$ & $854(45)$ & $8089(43)$ & 0.04 \\
\hline Renal replacement therapy & $1257(6)$ & $152(8)$ & $1105(6)$ & 0.09 \\
\hline AKI stage within $24 \mathrm{~h}$ & & & & 0.47 \\
\hline No AKI & $10,597(51)$ & $982(52)$ & $9615(51)$ & \\
\hline 1 & $3584(17)$ & $388(20)$ & $3196(17)$ & \\
\hline 2 & $1436(7)$ & $198(10)$ & $1238(7)$ & \\
\hline 3 & $1877(9)$ & $261(14)$ & $1616(9)$ & \\
\hline Missing & $3247(16)$ & $76(4)$ & $3171(17)$ & \\
\hline 30-day mortality & $4367(21)$ & $346(18)$ & $4021(21)$ & 0.08 \\
\hline
\end{tabular}

Data are expressed as no. (\%) or median [IQR]

*As general guidance, it is suggested that effect sizes are likely to be "small" when an SMD approximates 0.2 , likely to be "medium" when an SMD is 0.5 , and "large" when an SMD is higher than 0.8

${ }^{\dagger}$ In total, data are missing for $19(0.1 \%)$ patients

SMD standardized mean difference, eGFR estimated glomerular filtration rate, ICU intensive care unit, SAPS-II Simple Acute Physiology Score II, AKI acute kidney injury

$24 \mathrm{~h}$ of ICU admission. However, the time until this difference disappeared was longer for patients with moderate to severe CKD or AKI (Fig. 1).

In this large cohort of critically ill patients, metformin users had higher lactate levels than nonusers in the early phase of critical illness, which disappeared within $24 \mathrm{~h}$ of
ICU admission. Importantly, the difference in lactate levels between metformin users and nonusers was higher in patients with more severe AKI, while the difference was almost similar across preadmission eGFR subgroups. This may be explained by reduced clearance of metformin or lactate, or both. A limitation is that blood metformin 


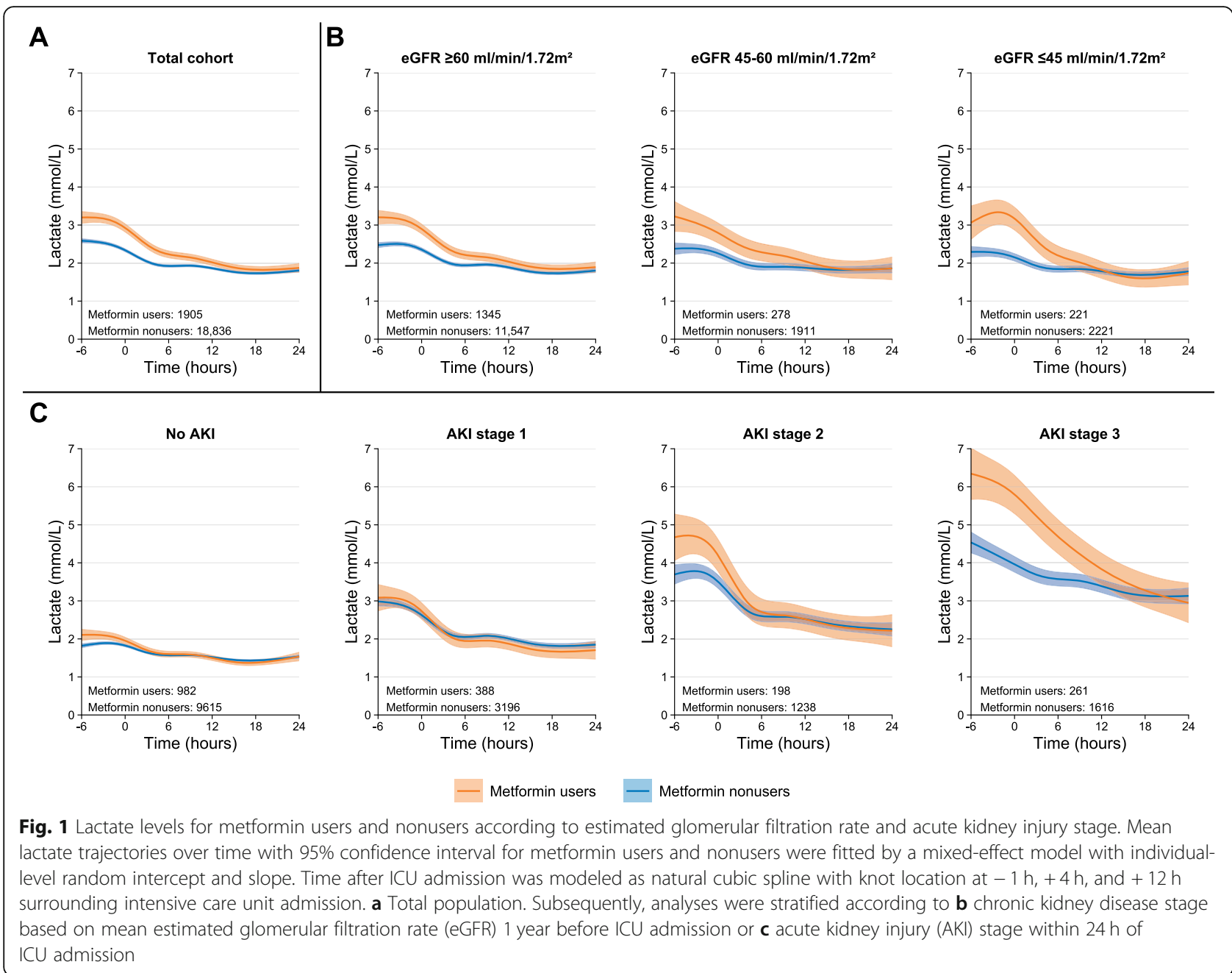

concentrations were unavailable to confirm this because such correlation was found in patients receiving renal replacement therapy for metformin-associated lactic acidosis [6].

The monitoring of lactate trajectories is recommended during critical illness [3]. Awareness of factors affecting this biomarker will improve its interpretation. We report that the association of metformin use with increased lactate levels is more pronounced in patients who develop AKI stage 2 or 3 than in patients without AKI or who develop AKI stage 1.

\section{Abbreviations}

CKD: Chronic kidney disease; ICU: Intensive care unit; eGFR: Estimated glomerular filtration rate; AKI: Acute kidney injury; KDIGO: Kidney Disease Improving Global Outcomes; SMD: Standardized mean difference

\section{Acknowledgements}

We want to thank Trine Frøslev, MSc (Department of Clinical Epidemiology, Aarhus University Hospital, Aarhus, Denmark), for the acquisition of data and Daan J. Touw, PharmD, PhD (Department of Clinical Pharmacy and Pharmacology, University Medical Center Groningen, Groningen, The Netherlands), for interpretation of data and critically revising the manuscript for important intellectual content. Both received no additional compensation for the work provided.

\section{Authors' contribution}

All authors contributed to the study conception and design, and analysis and/or interpretation of the data. RAP, AH, and CFC collected data and performed the analyses. RAP wrote the first draft of the manuscript. All authors critically reviewed and edited the manuscript, and all authors read and approved the final version. RAP and CFC had full access to all of the data in the study and take responsibility for the integrity of the data and the accuracy of the data analysis.

\section{Funding}

RAP was supported by a grant from the Aarhus University Research Fund and the Van Leersum Grant of the Royal Netherlands Academy of Arts and Sciences. AH received support provided by the Steno Diabetes Center Aarhus, which is partially funded by an unrestricted donation from the Novo Nordisk Foundation. The funder had no role in the design and conduct of the study; collection, management, analysis, and interpretation of the data; preparation, review, or approval of the manuscript; and decision to submit the manuscript for publication.

\section{Availability of data and materials}

Parts of the data that support the findings of this study are available from the Danish Health Data Authority (Sundhedsdatastyrelsen), but restrictions apply to the availability of these data, which were used under license for the present study and are thus not publicly available. 


\section{Ethics approval and consent to participate}

The Danish Data Protection Agency approved the study (record number 2015-57-0002, Aarhus University record number 2016-051-000001/432). According to Danish law, no ethical approval or informed consent was required for this registry-based study.

\section{Consent for publication}

Not applicable.

\section{Competing interests}

The authors declare that they have no competing interests.

\section{Author details}

'Department of Critical Care, University of Groningen, University Medical Center Groningen, Groningen, The Netherlands. ${ }^{2}$ Department of Clinical Epidemiology, Aarhus University Hospital, Aarhus, Denmark. ${ }^{3}$ Steno Diabetes Center Aarhus, Aarhus University Hospital, Aarhus, Denmark. ${ }^{4}$ Department of Renal Medicine, Aarhus University Hospital, Aarhus, Denmark.

Received: 11 July 2020 Accepted: 20 September 2020

Published online: 29 September 2020

\section{References}

1. Inzucchi SE, Lipska KJ, Mayo H, Bailey CJ, McGuire DK. Metformin in patients with type 2 diabetes and kidney disease: a systematic review. JAMA. 2014; 312:2668-75.

2. Davies MJ, D'Alessio DA, Fradkin J, et al. Management of hyperglycemia in type 2 diabetes, 2018. A consensus report by the American Diabetes Association (ADA) and the European Association for the Study of Diabetes (EASD). Diabetes Care. 2018:41:2669-701.

3. Levy MM, Evans LE, Rhodes A. The Surviving Sepsis Campaign bundle: 2018 update. Crit Care Med. 2018;46(6):997-1000.

4. Posma RA, Frøslev T, Jespersen B, et al. Prognostic impact of elevated lactate levels on mortality in critically ill patients with and without preadmission metformin treatment: a Danish registry-based cohort study. Ann Intensive Care. 2020;10:36.

5. Siew ED, Ikizler TA, Matheny ME, et al. Estimating baseline kidney function in hospitalized patients with impaired kidney function. Clin J Am Soc Nephrol. 2012;7:712-9.

6. Yeh HC, Ting IW, Tsai CW, Wu JY, Kuo CC. Serum lactate level and mortality in metformin-associated lactic acidosis requiring renal replacement therapy: a systematic review of case reports and case series. BMC Nephrol. 2017;18:229.

\section{Publisher's Note}

Springer Nature remains neutral with regard to jurisdictional claims in published maps and institutional affiliations.

Ready to submit your research? Choose BMC and benefit from:
- fast, convenient online submission
- thorough peer review by experienced researchers in your field
- rapid publication on acceptance
- support for research data, including large and complex data types
- gold Open Access which fosters wider collaboration and increased citations
- maximum visibility for your research: over 100M website views per year
At BMC, research is always in progress.
Learn more biomedcentral.com/submissions

